\title{
Trail of labor versus elective repeat cesarean section: a comparison of morbidity and mortality at tertiary care teaching hospitals in India
}

\author{
Balwan Singh Dhillon ${ }^{1 *}$, Nomita Chandhiok ${ }^{2}$, M. Vishnu Vardhana Rao ${ }^{3}$
}

${ }^{1}$ Scientist-G, ${ }^{2}$ Ex-Scientist-G, Indian Council of Medical Research, Ansari Nagar, New Delhi, India
${ }^{3}$ Director, ICMR-National Institute of Medical Statistics, Ansari Nagar, New Delhi, India

Received: 05 September 2018

Accepted: 05 October 2018

\section{*Correspondence:}

Mr. Balwan Singh Dhillon,

E-mail: balwandhillon@gmail.com

Copyright: $\odot$ the author(s), publisher and licensee Medip Academy. This is an open-access article distributed under the terms of the Creative Commons Attribution Non-Commercial License, which permits unrestricted non-commercial use, distribution, and reproduction in any medium, provided the original work is properly cited.

\section{ABSTRACT}

Background: As cesarean birth rates continue to rise, more women are faced with the choice of planning a vaginal delivery or a repeat cesarean section after a previous cesarean section. The objective of this prospective study was to study the morbidities and mortality of women attempting a trial of labor after cesarean (TOLAC) versus elective repeat cesarean section (El-RCS).

Methods: Prospective data was recorded on management practices, associated complications and morbidity \& mortality for a period of 8 months on 15664 consecutive cases of previous cesarean section reporting at 30 medical colleges/ teaching hospitals for delivery.

Results: A trial of labor was planned in 25.8\% (4035) women and 34.5\% (5399) women underwent elective repeat cesarean section and rest had emergency repeat cesarean section. Overall maternal morbidity due to any cause was $20.7 \%$ among El-RCS as compared to $14.2 \%$ in TOLAC which was statistically significant (OR: 1.57, CI: $1.41-1.76$, $\mathrm{P}=0.00$ ). Blood loss of more than $1000 \mathrm{ml}$ was around $8.0 \%$ among TOLAC where as in El-RCS it was $8.8 \%$ (OR: 0.89 , CI: $0.77-1.94, \mathrm{p}=0.14$ not statistically significant). Blood transfusion was given in $3.7 \%$ in TOLAC where as in El-RCS it was given in 6.5\% (OR: $0.56, \mathrm{CI}: 0.45-0.68, \mathrm{p}=0.00$ highly significant). Complication like dehiscence of scar was similar in both groups. Post-operative complication were seen in $2.8 \%$ cases in TOLAC where as in El-RCS it was $5.8 \%$ (OR: $0.47, \mathrm{CI}: 0.38-0.59, \mathrm{p}=0.00$ highly significant). Uterine rupture was $0.3 \%$ in TOLAC where as in ElRCS it was $0.7 \%$ (OR: 0.43 , CI: $0.21-0.87, p=0.009$ statistically significant). Maternal mortality was reported in $0.2 \%$ cases of TOLAC as compared to $0.1 \%$ cases in El-RCS $(\mathrm{p}=0.17)$ which was not statistically significant.

Conclusions: Maternal morbidity was found to be more in elective repeat cesarean section than trial of labor after cesarean section.

Keywords: Elective repeat cesarean section, Maternal, Morbidity and mortality, Trial of labor after cesarean

\section{INTRODUCTION}

As cesarean birth rates continue to rise, more women are faced with the choice of planning a vaginal or a repeat cesarean birth after a previous cesarean section. While there are risks and benefits for both vaginal birth after cesarean (VBAC) or repeat cesarean section. For many decades, there has been a public health concern about increasing cesarean section rates. In 1916 Cragin made a statement "once a cesarean, always a cesarean" was revised in many countries, and a trial of labor in women with history of cesarean section was proposed as an attempt to reduce cesarean section rates and subsequent maternal and neonatal morbidity. ${ }^{1-4}$

Trial of labor after cesarean is defined as the plan to attempt labor when a woman has had a previous cesarean birth, with the goal of achieving a successful vaginal 
birth. Elective repeat cesarean section is defined as a cesarean delivery performed before the onset of labor. Cesarean delivery is one of the most commonly performed surgical procedures and elective repeat Cesarean section (El-RCS) accounts for a large proportion of cesarean section. ${ }^{5} \mathrm{VBAC}$ is a safe option for many women. ${ }^{6}$

VBAC offers distinct advantages over repeat cesarean section, since the operative morbidity and mortality are completely eliminated, the hospital stay is much reduced, and the expenses involved are much less.

The rate of cesarean section needs to be reduced and this can be achieved to a small extent by avoiding a primary cesarean section done without explicit indications and more importantly, by resorting to a trial of vaginal delivery after previous cesarean section, which is safe for the fetus. ${ }^{7,8}$

The present study was undertaken to study the maternal morbidity and mortality in women who underwent either a TOLAC or an El-RCS after a previous cesarean section.

\section{METHODS}

A hospital based maternal health database was established at 30 medical colleges/teaching hospitals situated all over the country and prospective data was recorded for a period of 8 months in 2005-2006 on management practices, associated complications, morbidity and mortality in 15664 consecutive cases of previous cesarean section reporting for delivery. Structured case record forms were completed by trained medical research staff.

The study population was divided into 2 groups based on whether the woman underwent a trial of labor after cesarean (TOLAC) or an elective repeat cesarean section. (El-RCS) as the mode of delivery.

Both groups (TOLAC and El-RCS) were compared with regard to any type of maternal morbidity, uterine rupture/dehiscence, and emergency interventions like blood transfusion and hysterectomy.

Inclusion criteria was that all the women with history of one prior cesarean delivery at tertiary care teaching hospitals were included in the study after obtaining informed consent.

\section{Statistical analysis}

The data collected were coded and fed into the computer using Epi-Info and exported to the Statistical Package for Social Science. Statistical analysis was performed using SPSS 20.0 for windows and various descriptive statistics were used to calculate frequencies, percentages, means and standard deviation and to find association chi square test was used.

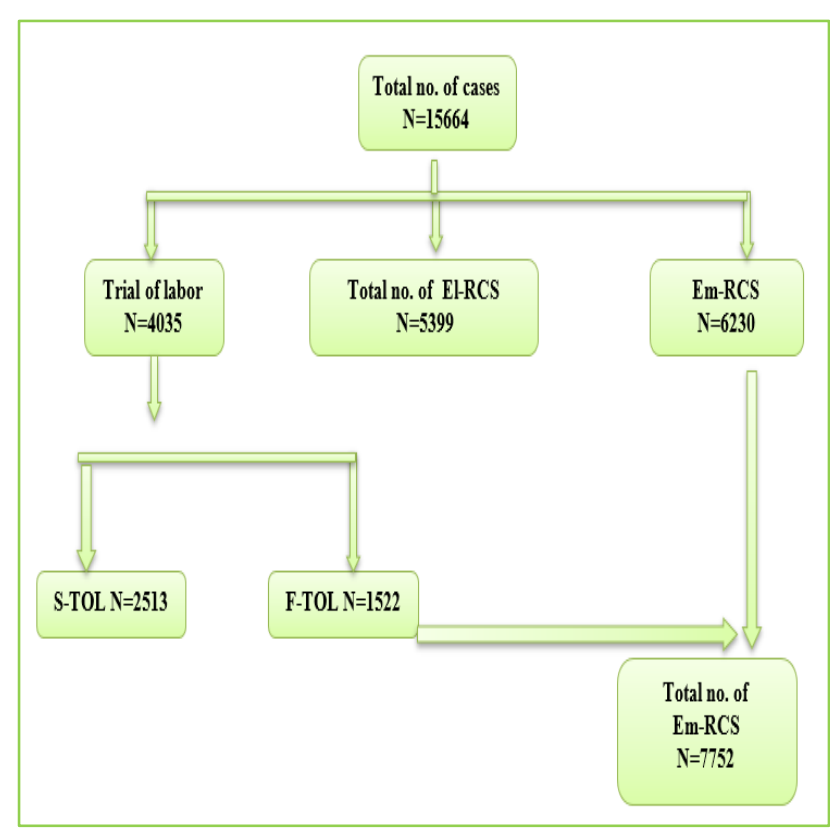

Figure 1: Diagrammatic representation of the selection of the study population.

\section{RESULTS}

Of the 15664 women with a previous cesarean section, $25.8 \%$ (4035) chose to undergo a trial of labor and $34.5 \%$ (5399) elected an elective repeat cesarean section. The rest had emergency repeat cesarean for various indications.

The mean age of women who had TOLAC was 26.0 \pm 3.8 years. The value for those who had El-RCS was 26.5 \pm 4.0 years. The difference in their mean age was statistically significant $(\mathrm{P}=0.00)$.

Women less than 25 years were more likely to attempt a trial of labor than to undergo elective repeat cesarean section. More than $70 \%$ of the women who had TOLAC and El-RCS were in their second delivery (OR: 0.81, CI: 0.74-0.89, P: 0.00). More number of women was booked in El-RCS $(70.4 \%)$ as compared to TOLAC $(64.9 \%)$. The characteristics of the women in the two groups are shown in Table 1.

Table 2 shows the overall maternal morbidity due to any cause was $20.7 \%$ among El-RCS as compared to $14.2 \%$ in TOLAC which was statistically significant (OR: 1.57, CI: $1.41-1.76, \mathrm{P}=0.00)$.

The difference in any morbidity was statistically significant $(\mathrm{P}=0.00)$. Blood loss of more than $1000 \mathrm{ml}$ was around $8.0 \%$ among TOLAC where as in El-RCS it was $8.8 \%$ (OR: 0.89 , CI: $0.77-1.94, \mathrm{p}=0.14$ not statistically significant). Blood transfusion was given in $3.7 \%$ in TOLAC where as in El-RCS it was given in $6.5 \%$ (OR: 0.56, CI: $0.45-0.68, \quad \mathrm{p}=0.00$ highly significant). Complication like dehiscence of scar in TOLAC was 88 $(2.2 \%)$ as compared to $119(2.2 \%)$ in El-RCS ( $\mathrm{p}=0.000)$. 
Table 1: Characteristics of pregnant women undergoing trial of labor or an elective repeat cesarean section.

\begin{tabular}{|c|c|c|c|c|}
\hline Characteristics & Trial of labor $(\mathrm{n}=4035)$ & $\begin{array}{l}\text { Elective repeat cesarean } \\
\text { section }(n=5399)\end{array}$ & Odds ratio (95\% CI) & p-value \\
\hline \multicolumn{5}{|c|}{ Maternal age (years) } \\
\hline$<=19$ & $34(0.8)$ & $40(0.7)$ & $1.14(0.7-1.85)$ & \multirow{6}{*}{0.00} \\
\hline $20-24$ & $1488(36.9)$ & $1747(32.4)$ & $1.22(1.12-1.33)$ & \\
\hline $25-29$ & $1765(43.7)$ & $2377(44.0)$ & $0.99(0.91-1.08)$ & \\
\hline $30-34$ & $605(15.0)$ & $962(17.8)$ & $0.81(0.73-0.91)$ & \\
\hline$>=35$ & $143(3.5)$ & $273(5.1)$ & $0.89(0.56-0.85)$ & \\
\hline Mean \pm SD & $26.0 \pm 3.8$ & $26.5 \pm 4.0$ & & \\
\hline \multicolumn{4}{|l|}{ Parity } & \multirow{6}{*}{0.00} \\
\hline 2 & $2868(71.1)$ & $4055(75.1)$ & $0.81(0.74-0.89)$ & \\
\hline 3 & $898(22.3)$ & $1121(20.8)$ & $1.09(0.99-1.21)$ & \\
\hline 4 & $201(5.0)$ & $162(3.0)$ & $1.69(1.36-2.11)$ & \\
\hline 5 & $50(1.2)$ & $40(0.7)$ & $1.68(1.08-2.62)$ & \\
\hline$>5$ & $18(0.4)$ & $21(0.4)$ & $1.15(0.58-2.26)$ & \\
\hline \multicolumn{4}{|l|}{ Booking status } & \multirow{3}{*}{0.00} \\
\hline Booked & $2620(64.9)$ & $3801(70.4)$ & (078) 71 (05) & \\
\hline Unbooked & $1415(35.1)$ & $1598(29.6)$ & $0.18(0.11-0.85)$ & \\
\hline \multicolumn{4}{|c|}{ Infant's birth weight } & \multirow{7}{*}{0.00} \\
\hline$<2500$ & $988(24.5)$ & $732(13.6)$ & $2.06(1.85-2.3)$ & \\
\hline $2500-2999$ & $1630(40.4)$ & $2125(39.4)$ & $1.04(0.96-1.14)$ & \\
\hline $3000-3499$ & $1105(27.4)$ & $1809(33.5)$ & $0.75(0.68-0.82)$ & \\
\hline $3500-3999$ & $246(6.1)$ & $490(9.1)$ & $0.65(0.55-0.77)$ & \\
\hline$\geq 4000$ & $31(0.8)$ & $67(1.2)$ & $0.61(0.39-0.95)$ & \\
\hline Not known & $35(0.9)$ & $176(3.2)$ & & \\
\hline
\end{tabular}

Table 2: Morbidity in pregnant women who chose atrial of labor or an elective repeat cesarean section.

\begin{tabular}{|c|c|c|c|c|}
\hline & $\begin{array}{l}\text { Trial of labor } \\
(n=4035)\end{array}$ & $\begin{array}{l}\text { Elective repeat cesarean } \\
\text { section }(n=5399)\end{array}$ & Odds ratio (95\% CI) & P-value \\
\hline Any morbidity & $574(14.2)$ & $1117(20.7)$ & $1.57(1.41-1.76)$ & 0.0 \\
\hline Anaesthetic complication & $16(0.4)$ & $46(0.9)$ & $0.46(0.25-.85)$ & 0.006 \\
\hline Complication during surgery & $62(1.5)$ & $145(2.7)$ & $0.57(0.41-.77)$ & 0.0002 \\
\hline Dehiscence of the scar & $88(2.2)$ & $119(2.2)$ & $0.99(0.74-1.32)$ & 0.94 \\
\hline Uterine rupture & $12(0.3)$ & $37(0.7)$ & $0.43(0.21-.87)$ & 0.009 \\
\hline Hemorrhage during surgery $>1000 \mathrm{ml}$ & $321(8.0)$ & $476(8.8)$ & $0.89(0.77-1.04)$ & 0.14 \\
\hline Broad ligament hemotoma & $3(0.1)$ & $13(0.2)$ & $0.31(0.07-1.117)$ & 0.052 \\
\hline Blood transfusion & $151(3.7)$ & $353(6.5)$ & $0.56(0.45-.68)$ & 0.00 \\
\hline Hysterectomy & $3(0.1)$ & $10(0.2)$ & $0.4(0.09-1.59)$ & 0.15 \\
\hline Post-operative complication & $114(2.8)$ & $313(5.8)$ & $0.47(0.38-0.59)$ & 0.0 \\
\hline
\end{tabular}

Post-operative complication was seen in $2.8 \%$ (114) cases in TOLAC where as in El-RCS was $5.8 \%$ (313) (OR: $0.47, \mathrm{CI}: 0.38-0.59, \mathrm{p}=0.00$ highly significant $)$. Uterine rupture was $0.3 \%$ (12) in TOLAC as compared to $0.7 \%$ (37) in El-RCS (OR: 0.43, CI: 0.21-0.87, $\mathrm{p}=0.009$ statistically significant). Maternal death was reported in $0.2 \%$ (10) cases of TOLAC as compared to $0.1 \%$ (5) cases in El-RCS $(\mathrm{p}=0.17)$ which was not statistically significant. The average duration of hospital stay for TOLAC was $4.5 \pm 3.9$ days as compared to El-RCS 10.6 \pm 5.0 . This shows that women who had a successful VBAC had a significantly lesser duration of hospital stay as compared to those had a cesarean section $(p=0.000$ highly significant) in TOLAC and IL-RCS respectively.
The rates of admission to a neonatal intensive care unit was $11.6 \%$ versus $11.2 \%$ (OR: $1.04, \mathrm{CI}: 0.91-1.18$, $\mathrm{p}=0.60$ not statistically significant) in TOLAC and ElRCS respectively.

\section{DISCUSSION}

There has been a steady increase in the rate of cesarean section even in the developing countries over the past few decades causing considerable professional concern. A total of 155863 deliveries took place in this study duration, out of which 43824 were the number of cesarean section and 15664 were the number of previous cesarean section. Of 15664 women with history of 
cesarean, 4035 women who were allowed a trial of labor, $2513(62.3 \%)$ delivered vaginally, 5399 (34.5\%) women underwent elective repeat cesarean section. There was failed trial of labor (F-TOL) in 1522 cases and requiring an emergency cesarean section for delivery of baby. Therefore, a total number of 7752 (49.5\%) women needed surgery in emergency.

Miller et al. reported a post cesarean pregnancy rate of $8.1 \%$ in 1983 and $14.1 \%$ in 1992.9 Bhat BPR et. al. reported post caesarean pregnancy rate of $8.7 \% .10$ Present study showed a post cesarean pregnancy rate of $10.1 \%$. In India and elsewhere have shown that trial of labor in a patient with previous cesarean section is not only safe but feasible. ${ }^{11-13}$ Although a trial of labor ends in vaginal delivery in $60 \%$ to $80 \%$ of women who attempt it after a previous cesarean section, we had a $62.3 \%$ success in those who had trial of labor. ${ }^{14-16}$ The most important issue regarding maternal safety with respect to a trial of labor after a previous cesarean section will occur and lead to serious morbidity or death. In present study maternal mortality was reported in $0.2 \%$ cases of TOLAC as compared to $0.1 \%$ cases in El-RCS which was not statistically significant.

The overall maternal morbidity in present study was $14.2 \%, 20.7 \%$ in TOLAC and El-RCS respectively which was highly significant $(\mathrm{p}=0.00)$. Most of the complications were more in women undergoing an elective cesarean section than in those undergoing a trial of labor which were similar to the findings of Flamm et al and Rosen et al. The frequency of uterine rupture in the TOLAC $(0.3 \%)$ was similar to that in other studies. ${ }^{17-19}$ The number of hysterectomies, a complication for a woman of reproductive age, was similar in the two groups. Post-operative complication $(5.8 \%)$ contributed more morbidity among women who chose a El-RCS. Women for whom a trial of labor was unsuccessful and who therefore require a second cesarean section have the greatest morbidity. ${ }^{20}$

The rates of admission to a neonatal intensive care unit was $11.6 \%$ versus $11.2 \%$ (OR: 1.04 , CI: 0.91-1.18, $\mathrm{p}=0.60$ not statistically significant) in TOLAC and ElRCS respectively. The average duration of hospital stay for TOLAC was $4.5 \pm 3.9$ days as compared to El-RCS 10.6 \pm 5.0 . This shows that women who had a TOLAC had a significantly lesser duration of hospital stay as compared to those had an El-RCS ( $\mathrm{p}=0.000$ highly significant). This was comparable with other studies.

However, there is as yet no confirmed method of predicting the likelihood that a trial of labor will lead to vaginal delivery for a patient with a previous cesarean section. Randomised controlled trials are required to provide the most reliable evidence regarding the benefits and harms of both trial of labor and elective repeat cesarean section for women with a previous cesarean section. Maternal morbidity and mortality needs to be studied in greater detail.

\section{CONCLUSION}

Maternal morbidity was found to be more in elective repeat cesarean section than trial of labor after cesarean section.

\section{ACKNOWLEDGMENTS}

Principal co-investigators (in alphabetic order):

Bharti S., Egmore, Chennai; Bhatia P., Kasturba Hospital, New Delhi; Coyaji K.J., KEM Hospital, Pune; Das M.C., Guwahati Medical College, Guwahati; ; Das V., CSMM University, Lucknow; Davar R.G., Sir J.J. Group of Hospital, Bombay; Devambigai S., Govt. RSRM Hospital, Chennai; Ganguly G., MLN Medical College, Allahabad; Ghosh T.K., P.G.I.M.E.R. \& SSKM Hospital, Calcutta; Gopalan S., PGIMER, Chandigarh; Idnani R., LLRM Medical College, Meerut; Kochar S., S.P.Medical College , Bikaner; Kodkany B.S., JLN medical college, Belgaum; Madhini V., Govt. K.G.Hospital, Chennai; Mittal S., AIIMS, New Delhi; Mukherjee J., R.G.Kar Medical College, Calcutta; Naphade P.R., B.J. .Medical College, Pune; Nevrekar P., Goa Med College, Goa; Padmanaban I., Kilpauk Medical College, Chennai; Pagi S.L., SSGS Medical College, Baroda; Patnaik S., SCB Medical College, Cuttack; Rajarajeswari S., Madurai Medical College, Madurai; Salhan S., Safdarjung Hospital, New Delhi; Salvi V., K.E.M. Hospital, Bombay; Sanghamitra M., Eden Hospital, Calcutta; Sharma S., Patna Medical College, Patna; Sharma S., SMGS Hospital, Jammu; Soni I.J.K., GSVM Medical College, Kanpur; Sulekha P.B., SAT Medical College, Thiruvanathapuram; Taly A., SMS Medical College, Jaipur.

Funding: No funding sources

Conflict of interest: None declared

Ethical approval: The study was approved by the Institutional Ethics Committee

\section{REFERENCES}

1. Craigin EB. Conservatism in obstetrics. New York Med J. 1916;104:1-3.

2. Rosen MG, Dickinson JC, Westhoff CL. Vaginal birth after cesarean: a meta-analysis of morbidity and mortality. Obstet Gynecol. 1991;77(3):465-70.

3. Mozurkewich EL, Hutton EK. Elective repeat cesarean delivery versus trial of labor: a metaanalysis of the literature from 1989 to 1999. Am J Obstet Gynecol. 2000;183(5):1187-97.

4. American College of Obstetricians and Gynecologist Vaginal Birth After Previous Cesarean Delivery Practice Bulletin No 115. Washington, DC: American College of Obstetricians and Gynecologist 2010; 116(2):450-463.

5. Vogel JP, Betran AP, Vindevoghel N, Souza JP, Torloni MR, Zhang J, et al. Use of the Robson classification to assess caesarean section trends in 21 
countries: a secondary analysis of two WHO multicountry surveys. Lancet Glob Health 2015;3(5):e260-270.

6. Guise JM. Vaginal delivery after caesarean section. Br Med J. 2004; 329:359-60.

7. Pridjian G, hibbard JU, moawad AH .cesarian: changing the trends. Obstet Gynecol 1991;77(7462): 195-200.

8. Sachs BP, Kobelin C, Castro MA, Frigoletto F. Yhe risk of lowering the cesarian delivery rate. New Eng J Med 1999;340(1);54-7

9. Miller AD, Diaz FG, Paul RH. Vaginal birth after caesarean: a 10-year experience. Obstet Gynecol. 1994;84(2):255-8.

10. Bhat BPR, Savant R, Kamath A. Outcome of a post caesarean pregnancy in a tertiary center of a developing country. J Clin Diag Res. 2010:4(1):2005-9.

11. Dhall K, Mittal SC, Grover V et al. Childbirth following primarycesarean section-evaluation of a scoring system. Int J Gynecol Obstet. 1987;25(3):199-201.

12. Singh T, Clark SC, Toffel S. Changes in cesarean delivery in the United States, 1988 and 1993. Birth 1995;22(2):63-7.

13. Mc Mohan MJ, Luther ER, Bowes WA et al. Comparison of a trial of labor with an elective second cesarean section. $N$ Engl $J$ Med. 1996;335(10):689-95.

14. Cowan RK, Kinch RA, Ellis B, Anderson R. Trial of labour following caesarean delivery. Obstet Gynecol 1994;83(6):933-6
15. Iloabachie CC. Delivery after a caesarean section. A review of 836 cases. Trop J Obstet Gynaecol. 1981;7:9-10

16. Ezechi OC, Nwokoro CA, Kalu BKE, Njokanma FO, Okeke GCE. Caesarean morbidity and mortality in a private hospital in Lagos Nigeria. Trop J Obstet Gynaecol. 2002;19:97-100

17. Flamm BL, Goings JR, Liu Y, Wolde-Tsadik G. Elective repeat cesarean delivery versus trial of labor: a prospective multicenter study. Obstet Gynecol. 1994;83(6):927-32.

18. Gellman E, Goldstein MS, Kaplan S, Shapiro WJ. Vaginal delivery after cesarean section: experience in private practice. JAMA 1983;249(21):2935-7.

19. Gibbs CE. Planned vaginal delivery following cesarean section. Clin Obstet Gynecol 1980;23(2):507-15.

20. Dhillon BS, Chandhiok N, Shukla DK. Maternal morbidity and mortality following a trial of labor in women with previous cesarean section at tertiary care teaching hospitals in India. J Med Sci Clinic Res. 2017;05(09):27587-92.

Cite this article as: Dhillon BS, Chandhiok N, Rao MVV. Trail of labor versus elective repeat cesarean section: a comparison of morbidity and mortality at tertiary care teaching hospitals in India. Int J Reprod Contracept Obstet Gynecol 2018;7:4476-80. 